\title{
Possible Formation of Living Polymers of $p$-Methoxystyrene by Iodine
}

\author{
Toshinobu Higashimura and Osamu Kishiro \\ Department of Polymer Chemistry, Kyoto University, \\ Yoshida, Sakyo-ku, Kyoto 606, Japan.
}

(Received September 20, 1976)

\begin{abstract}
Possibilities for long-lived propagating species in cationic polymerization of vinyl compounds were investigated. $p$-Methoxystyrene ( $p$-MOS) was polymerized with iodine as an initiator at $0^{\circ} \mathrm{C}$. In carbon tetrachloride the molecular weight of the polymers increased with increasing conversion. After the completion of the polymerization, $p$-MOS was added to cause a further increase of the molecular weight of the polymer. These features were not observed in the polymerization in polar solvents such as methylene chloride. On the basis of these findings, the nondissociated propagating species is considered to be long-lived, whereas the dissociated propagating species is considered to be short-lived. It is also pointed out that a long-lived growing chain is possibly involved in the polymerization of styrene with perchlorate anion as a counterion at low temperatures.
\end{abstract}

KEY WORDS $p$-Methoxystyrene / Styrene / Iodine / Acetyl Perchlorate / Cationic Polymerization / Living Polymer / Molecular Weight Distribution /

Since the living anionic polymerization of styrene $^{1,2}$ was reported, a search for the living system in addition polymerization has been made. In order to realize a living polymerization, the propagating species produced from a monomer must have a moderate stability. Carbanions fulfil this condition, so that a good many living anionic polymerizations have been found.

In cationic polymerization, however, almost no living polymerization have been reported, because carbocations produced from vinyl compounds are usually of low stability. The living cationic polymerization has so far been reported only for ring-opening polymerization of tetrahydrofuran. ${ }^{3}$ In the ring-opening polymerization of cyclic ethers, a growing chain carries an oxonium ion which is more stable than carbocations, and neither a termination nor a transfer reaction takes place.

Olah $^{4}$ has developed a technique to stabilize carbocations by using superacids which generate anions of low nucleophilicity. Kennedy, ${ }^{5}$ who became interested in this technique, tried to synthesize living polyisobutylene in the polymerization initiated by a superacid. Termination reactions did not occur as expected, whereas transfer reactions did take place; thus his idea went unrealized. This instance showed that in organic solvents dissociated propagating species (carbocation) cannot survive even when a superacid was used.

Dissociated propagating species are apt to liberate a proton to leave a double bond at the polymer end. It occurred to us that for a moderately stable carbocation, side reactions such as the proton elimination (chan transfer) could be of minor importance when the propagating species is non-dissociated. In the present investigation we tested this idea using $p$-methoxystyrene ( $p$-MOS), which forms a stable carbocation because of the electron-donating substituent, and iodine as an initiator, which produces a counterion of high nucleophilicity. The choice of the monomer and the initiator is based on our finding ${ }^{6}$ that, if the solvent for polymerization is suitably chosen, this polymerization yields a polymer with a bimodal molecular weight distribution and the lower molecular weight fraction is formed by the nondissociated propagating species. Polystyrenes produced by 
acetyl perchlorate was also examined for comparison.

\section{EXPERIMENTAL}

All the polymerization processes were carried out in a dry nitrogen atmosphere, as reported in the previous paper. $^{6}$ The polymerization system contained water of $0.2-0.3 \mathrm{mM}$ as impurity. To terminate the polymerization the solution was poured into a large amount of methanol, and the polymers precipitated were recovered.

The molecular weight distribution (MWD) of polymer was measured for a metyl ethyl ketone solution using gel permeation chromatography under the same conditions as described in the previous paper. ${ }^{6}$ With poly( $p$-methoxystyrene) $[\operatorname{poly}(p$-MOS $)]$ the elution volume has not been correlated with the molecular weight. In the present investigation an approximate molecular weight of poly( $p$-MOS) was estimated by assuming that the molecular weight of poly $(p-M O S)$ is the same as that of polystyrene at the same elution valume. This sort of approximate molecular weight is represented as (MW)s. The infrared spectra of polymers were recorded for $\mathrm{KBr}$ disks.

The materials used were purified as described in the previous paper. ${ }^{6}$

\section{RESULTS AND DISCUSSION}

\section{Polymerization of p-Methoxystyrene by Iodine}

$M W D$ of Poly ( $p$-MOS) Obtained by Iodine. As has already been reported, ${ }^{6}$ the MWD of poly( $p$-MOS) is strongly dependent on the solvent used in the polymerization initiated by iodine. The polymers produced in a polar solvent such as methylene chloride were of high molecular weight and possessed a unimodal MWD, and the polymers produced in a nonpolar solvent such as carbon tetrachloride were of low molecular weight and also possessed a unimodal MWD (see Figure 1). On the other hand, the polymers produced in an intermediately polar solvent such as chloroform or methylene chloride-carbon tetrachloride mixture possessed a bimodal MWD (see Figure 3). The weight fractions of the higher and lower molecular weight parts changed with the polarity of the solvent, but the molecular weight of the two peaks of the MWD curve did not change. Investigations on the effects of the solvent polarity and the common ion led to the conclusion that the higher molecular weight part of the polymer was produced by dissociated propagating species and the lower molecular weight part of the polymer was produced by nondissociated propagating species. For poly $(p-\mathrm{MOS})$ produced in the present invesigation $\left([\mathrm{M}]_{0}, 10\right.$ vol $\left.\% ; 0^{\circ} \mathrm{C}\right)$, (MW)s of the higher molecular weight part was $1-2 \times 10^{5}$ and that of the lower molecular weight part was ca. $1 \times 10^{4}$.

Dependence of the Molecular Weight on Conversion. The simplest way to find out the presence of a living growing chain in addition polymerization is to examine the increase in the polymer molcular weight with the conversion of polymerization. The peak of the MWD curve for poly $(p$-MOS) produced in methylene chloride shifted slightly to a lower molecular weight as the polymerization proceeded. This has usually been observed in cationic poylmerization, and could indicate the involvement of short-lived growing chains.

On the other hand, a completely different

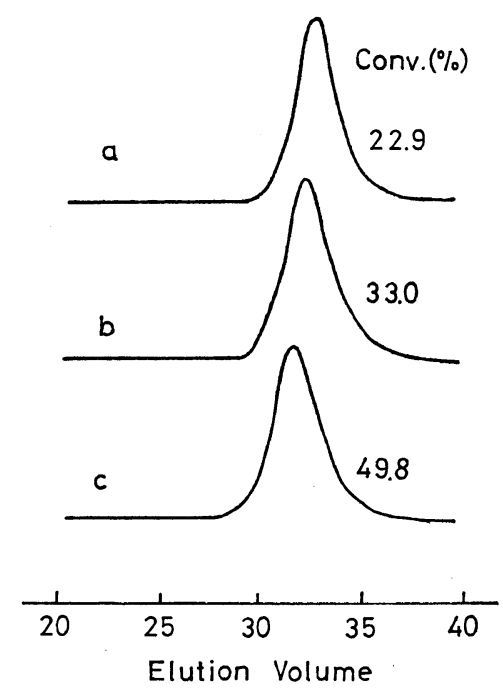

Figure 1. Effect of conversion on the MWD of poly $\left(p\right.$-MOS) obtained in $\mathrm{CCl}_{4}:[\mathrm{M}]_{0}, 10 \mathrm{vol} \%$; $\left[\mathrm{I}_{2}\right]$, $5.0 \mathrm{mM} ; 0^{\circ} \mathrm{C}$. (MW)s at the peak of MWD curve: a, 8200; b, $11000 ; \mathrm{c}, 14000$. 


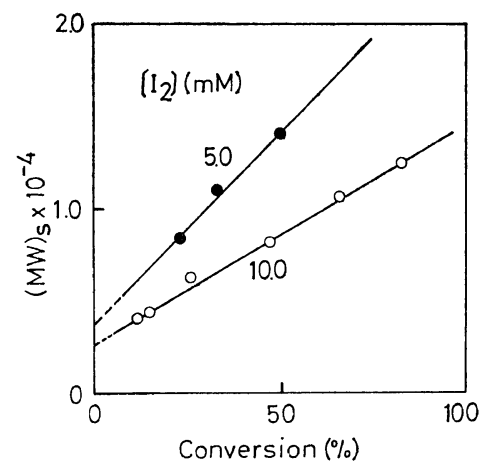

Figure 2. Relationship between (MW)s at the peak of MWD curve and the conversion: $\left[\mathrm{M}_{0}\right], 10 \mathrm{vol} \%$; solvent, $\mathrm{CCl}_{4} ; 0^{\circ} \mathrm{C}$.

behavior was observed in carbon tetrachloride. As is seen in Figure 1, the peak of the MWD curve shifted to a higher molecular weight with increasing conversion. Figure 2 shows the relationship between the peak molecular weight of the MWD curve and the conversion of polymerization. The molecular weight increased almost linearly with increasing conversion, and became higher as the initiator concentration was decreased.

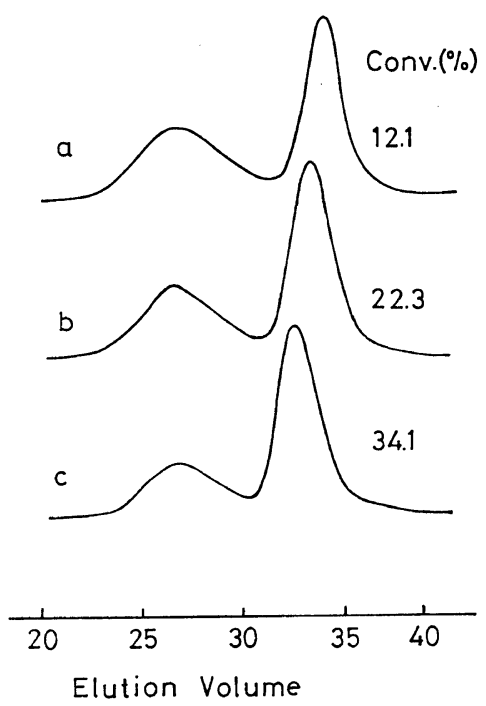

Figure 3. Effect of conversion on the MWD of poly $\left(p\right.$-MOS) obtained in $\mathrm{CH}_{2} \mathrm{Cl}_{2} / \mathrm{CCl}_{4}(2 / 1 \mathrm{v} / \mathrm{v})$ mixed solvent: $\left[\mathrm{M}_{0}\right], 10 \mathrm{vol} \% ;\left[\mathrm{I}_{2}\right], 3.3 \mathrm{mM}, 0^{\circ} \mathrm{C}$. (MW)s at the peak of MWD curve for the lower molecular weight polymers: a, 4700; b, 6000; c, 8000 .
The MWD curves of poly( $p$-MOS) obtained in a mixed solvent of methylene chloride and carbon tetrachloride are bimodal, as shown in Figure 3. The peak of the MWD curve for the higher molecular weight part shifted to a lower molecular weight, while that for the lower molecular weight, while that for the lower molecular weight part shifted to a higher molecular weight with increasing conversion. In the polymerization in chloroform just the same phenomena were observed. The peak molecular weight of the MWD curve for the lower molecular weight part is correlated with the conversion of polymerization in Figure 4. Both in chloroform and in the methylene chloride-carbon tetrachloride mixed solvent, the peak molecular weight of the lower molecular weight part was in linear relationship with the conversion.

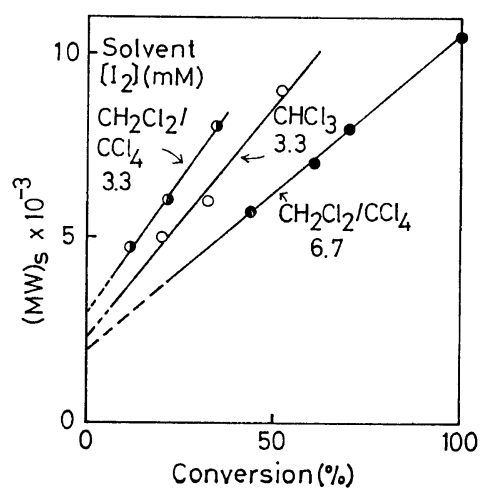

Figure 4. Relationship between (MW)s at the peak of MWD curve for the lower moleuclar weight polymers and the conversion in $\mathrm{CH}_{2} \mathrm{Cl}_{2} / \mathrm{CCl}_{4}$ $(2 / 1 \mathrm{v} / \mathrm{v})$ mixed solvent or in $\mathrm{CHCl}_{3}:[\mathrm{M}]_{0}, 10 \mathrm{vol} \%$; $0^{\circ} \mathrm{C}$.

The relationship between the conversion and the molecular weight of polymer produced in the presence of common ions was investigated as well. As reported in a previous paper ${ }^{6}$ the formation of the higher molecular weight part in the polymerization initiated by iodine is less favorable in the presence of tetra- $n$-butylammonium iodide. The relationship between the molecular weight of the lower molecular weight part and the conversion was investigated, the formation of the higher molecular weight part being minimized in the presence of the ammonium iodide. Under the condition of Figure 5, 


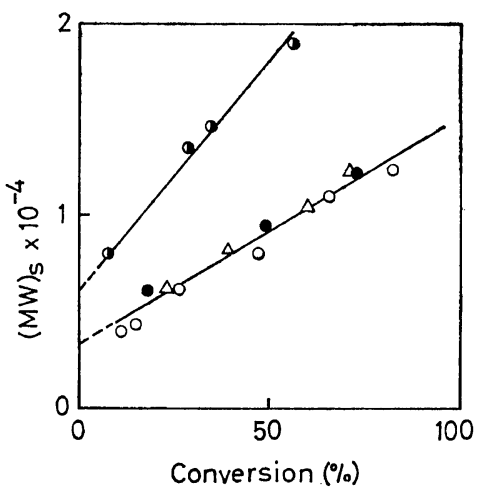

Figure 5. Relationship between (MW)s at the peak of the MWD curve and the conversion in the presence of $n \mathrm{Bu}_{4} \mathrm{NI}: \quad[\mathrm{M}]_{0}, 10 \mathrm{vol} \% ; 0^{\circ} \mathrm{C} ; \mathbf{O}$, $\mathrm{CH}_{2} \mathrm{Cl},\left[\mathrm{I}_{2}\right], 3.3 \mathrm{mM},\left[n \mathrm{Bu}_{4} \mathrm{NI}\right], 0.010 \mathrm{~m} M ; \triangle$, $\mathrm{CH}_{2} \mathrm{Cl}_{2} / \mathrm{CCl}_{4}(2 / 1 \mathrm{v} / \mathrm{v}), \quad\left[\mathrm{I}_{2}\right], 6.7 \mathrm{mM}, \quad\left[n \mathrm{Bu}_{4} \mathrm{NI}\right]$, $0.020 \mathrm{mM} ; \bigcirc, \mathrm{CCl}_{4},\left[\mathrm{I}_{2}\right], 10.0 \mathrm{mM}$, salt free; $\mathrm{CCl}_{4},\left[\mathrm{I}_{2}\right], 10.0 \mathrm{~m} M,\left[n \mathrm{Bu}_{4} \mathrm{NI}\right], 0.010 \mathrm{~m} M$.

only a low molecular weight poly ( $p$-MOS) with a unimodal MWD was produced either in methylene chloride or in the methylene chloridecarbon tetrachloride mixed solvent. The peak molecular weight increased with increasing conversion, as is shown in Figure 5. The molecular weight-conversion relationship for the polymerization in carbon tetrachloride either in the presence or in the absence of the ammonium iodide is also shown in Figure 5 for comparison. The common-ion effect is not observed in carbon tetrachloride at all. These findings indicate the similarity of the nondissociated propagating species in a nonpolar solvent to the propagating species that was made nondissociated by the addition of common ions.

Reasons for the increase in molecular weight with the progress of polymerization could be (i) a successive addition of monomer to a stable, long-lived propagating species, or (ii) side reactions such as Friedel-Crafts alkylation of a polymer by a growing chain to cause branching. A formation of branched polymer has been reported $^{7-9}$ for the polymerization of styrene with a metal halide in polar solvents such as nitrobenzene. Branching of polystyrene has also been reported ${ }^{10}$ when the polystyrene is treated with a high concentration of metal halide at high temperatures. In the polymerization of $p$-MOS by iodine, however, the molecular weight of polymer did not increase with increasing conversion in polar solvents, and it decreased with increasing initiator concentration in nonpolar solvents. These experimental facts suggest that the polymer molecular weight did not increase as a result of side reactions such as branching.

Two Stage Polymerization and the Change of Molecular Weights of Poly(p-MOS). If further monomer is added after stable, long-lived growing chains have consumed all the monomers originally present, the reinitiation of the polymerization and the formation of polymers having increased molecular weight are expected. This was tested for the polymerization in carbon tetrachloride, and the experimental results are shown in Figure 6. At 93-\% conversion of the first polymerization ( $p$-MOS, 10 vol \%; polymerization time, $5 \mathrm{hr}$ ), $6 / 5$ times as much $p$-MOS as that originally present was added. The MWD curve for the total polymer showed tailing toward a lower molecular weight, but with a limited extent. This unambiguously indicates that the molecular weight of the original polymers increased during the polymerization of the new monomer. The peak molecular weight increased almost linearly as the polymerization proceeded either before or after the monomer

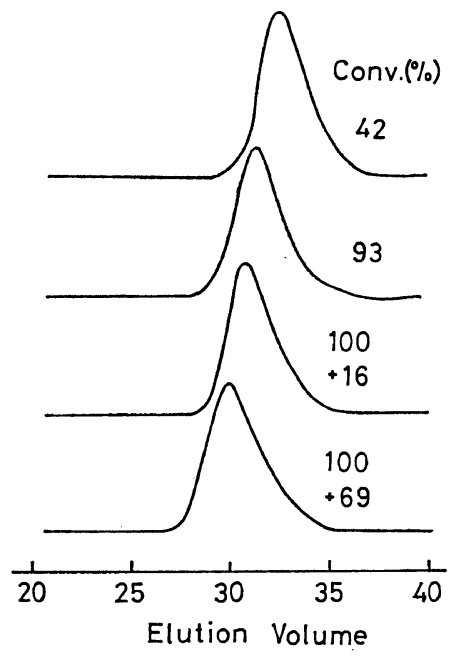

Figure 6. Effect of conversion on the MWD of poly( $p$-MOS) obtained in $\mathrm{CCl}_{4}$ before and after the monomer addition: $\left[\mathrm{I}_{2}\right]_{0}, 10.0 \mathrm{mM} ; 0^{\circ} \mathrm{C}$. After $93 \%$ of the initial monomers $\left([\mathrm{M}]_{0}, 10 \mathrm{vol} \%\right)$ were consumed, $p$-MOS (amount, 6/5 [M] $]_{0}$ ) was added. 


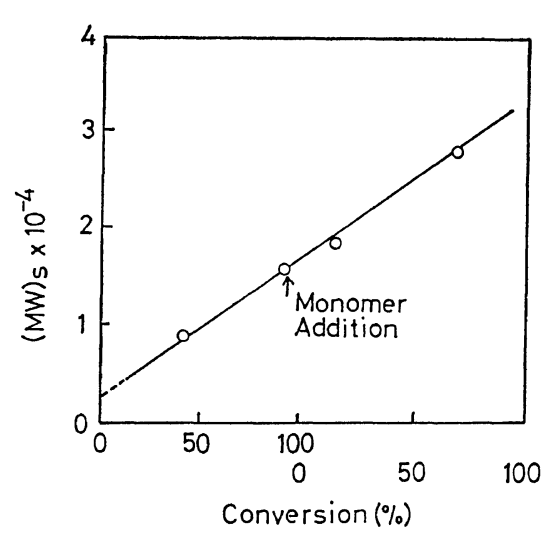

Figure 7. Relationship between (MW)s at the peak of the MWD curve and the conversion in $\mathrm{CCl}_{4}$ before and after the monomer addition. Polymerization conditions are the same as in Figure 6.

addition, which is shown in Figure 7. This implies that at the end of the first polymerization the growing chains are still alive.

The same sort of observation was also made for the polymerization in the methylene chloride-carbon tetrachloride $(2: 1)$ mixed solvent. Polymers produced in this solvent possessed a bimodal MWD. When the first polymerization $(p$-MOS, $10 \mathrm{vol} \%)$ went to near-completion

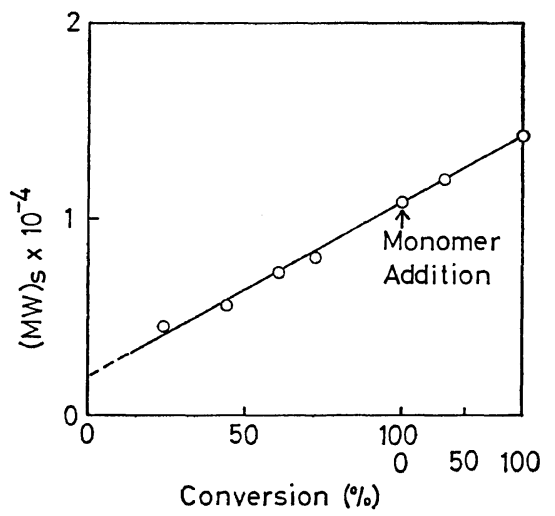

Figure 8. Relationship between (MW)s at the peak of the MWD curve for the lower molecular weight polymers and the conversion in $\mathrm{CH}_{2} \mathrm{Cl}_{2} / \mathrm{CCl}_{4}$ $(2 / 1 \mathrm{v} / \mathrm{v})$ mixed solvent before and after the monomer addition: $\left[\mathrm{I}_{2}\right]_{0}, 6.7 \mathrm{mM} ; 0^{\circ} \mathrm{C}$. After the initial monomers $\left([\mathrm{M}]_{0}, 10 \mathrm{vol} \%\right)$ were consumed nearly completely, $p$-MOS (amount, 2/5 $[\mathrm{M}]_{0}$ ) was added. (polymerization time, $3 \mathrm{hr}$ ), 2/5 times as much $p$-MOS as that initially present was added. The proportion of the higher and the lower molecular weight fractions was similar before and after the addition of monomer. The molecular weight of $\operatorname{poly}(p-\mathrm{MOS})$ in the higher molecular weight part somewhat decreased on the addition of monomer, while that in the lower molecular weight part increased almost linearly as the polymerization proceeded, as Figure 8 shows. These experimetal results indicate that the growing chains giving rise to the lower molecular weight polymers are as stable and long-lived as those in carbon tetrachloride.

Dependence of the Number of Polymer Molecules on Conversion. It is no doubt acceptable that the long-lived propagating species of $p$-MOS is produced when the polymerization is carried out in nonpolar solvents with iodine as an initiator, thus keeping the propagating species nondissociated. However, this polymerization system is not so perfect a living one as the living anionic polymerization of styrene. In a perfectly living polymerization, termination and transfer reactions are absent and the initiation is much faster than the propagation reaction. The above situation should lead to the condition that the initiator concentration is equal to the concentration of growing chains. The numbers of polymer molecules $(N)$ produced per unit molecule of initiator were calculated according to eq 1 and are shown in Figure 9. (MW)s

$$
N=\frac{[\mathrm{M}]_{\text {consumed }}}{\overline{\boldsymbol{P}}_{n}} \times \frac{1}{[\mathrm{C}]_{0}}
$$

was assumed to be the number average molecular weight of poly ( $p$-MOS) and substituted into eq 1 to calculate $N$. Although the mechanism of the initiation by iodine has not been made clear, one iodine molecule was assumed to participate in the reaction. (If two molecules of iodine are involved in the initiation, $N$ should be doubled.) These assumptions are quite conventional and inadequate to estimate the absolute value of $N$, but they were still employed to see the change of $N$ with the conversion.

As shown in Figure 9, the number of polymer molecules produced per unit molecule of initiator increased with increasing conversion. Similar 


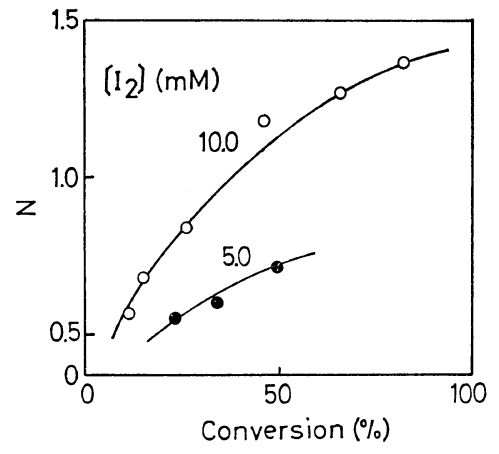

Figure 9. Relationship between the numbers of polymer chains produced per unit molecule of initiator $(N)$ and the conversion in $\mathrm{CCl}_{4} ;[\mathrm{M}]_{0}$, 10 vol $\% ; 0^{\circ} \mathrm{C}$.

observations were made with the low molecular weight polymers produced either in the methylene chloride-carbon tetrachloride mixed solvent or in the presence of tetra- $n$-butylammonium iodide. This event could be ascribed to a slow initiation and/or a minor transfer (or termination) reaction.

\section{Polymerization of Styrene with Perchlorate Coun- terion at Low Temperatures}

Possibilities for a long-lived growing chain in other cationic polymerization systems were investigated. In the previous paper, ${ }^{6}$ the formation of polystyrene with a bimodal MWD has been reported for the polymerization in methylene chloride with perchlorate anion as a counterion. At $0^{\circ} \mathrm{C}$ the molecular weight of the lower polymers was almost unchanged during the polymerization. On the other hand, at $-78^{\circ} \mathrm{C}$, the molecular weight of the lower polymers increased distinctly with increasing conversion (see Figures 3 and 4, Tables 1 and 2 of previous paper). ${ }^{6}$ Pepper $^{11,12}$ observed the same behavior in the polymerization of styrene by perchloric acid in methylene chloride below $-45^{\circ} \mathrm{C}$.

To explain the different behaviors of the polymerizations at $0^{\circ} \mathrm{C}$ and at $-78^{\circ} \mathrm{C}$, the terminal structue of polystyrene was examined with infrared spectroscopy. Polystyrenes having a bimodal MWD were separated into a higher molecular weight part and a lower molecular weight part by thin-layer chromatography. ${ }^{13}$ Infrared spectra are compared in Figure 10 for the

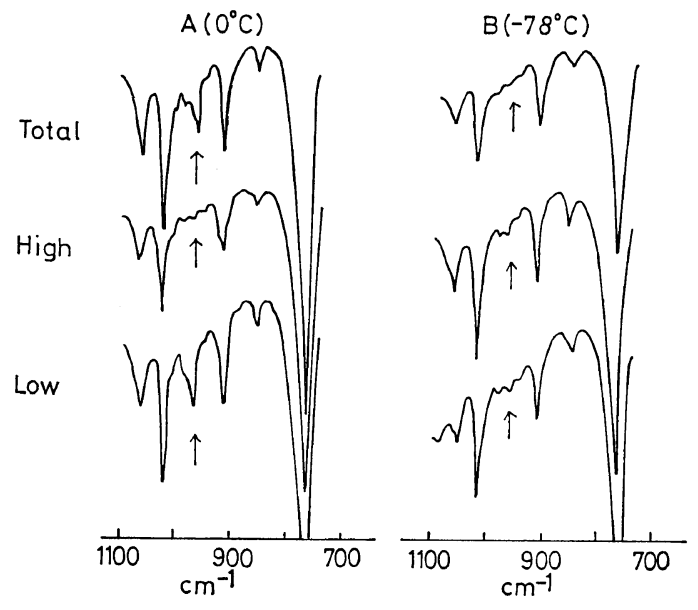

Figure 10. Infrared spectra of polystyrene obtained by $\mathrm{AcClO}_{4}$ in $\mathrm{CH}_{2} \mathrm{Cl}_{2}:[\mathrm{M}]_{0}, 1.0 \mathrm{M} ; \mathrm{A}, 0^{\circ} \mathrm{C}$, [ $\left.\mathrm{AcClO}_{4}\right], 0.40 \mathrm{~m} M$, conv., 55\%; B, $-78^{\circ} \mathrm{C}$, [AcClO $\mathrm{Al}_{4}$, $8.0 \mathrm{mM}$, conv., 36\%.

unfractionated polymer (designated as Total), the higher molecular weight part (designated as High), and the lower molecular weight part (designated as Low). The terminal structure of the higher molecular weight polymers could not be analyzed by the infrared spectroscopy. On the other hand, the lower molecular weight polymers (the molecular weights at the peak of MWD curve were 1400 and 1600 for the polymers A and B, respectively) exhibited a spectrum dependent on the polymerization temperature. The polymers produced at $0^{\circ} \mathrm{C}$ showed a strong absorption at $960 \mathrm{~cm}^{-1}$ which was ascribed to a terminal unsaturation, while the polymers produced at $-78^{\circ} \mathrm{C}$ did not show this absorption. As judged from the change of molecular weight with the conversion of polymerization, transfer reactions associated with a proton elimination is not so important and the terminal unsaturation is undetectable by infrared spectroscopy.

In the polymerization of styrene as well as $p$-MOS, it was suggested that nondissociated propagating species involve long-lived ones at low temperatures.

This investigation was supported by a research grant from the Ministry of Education, Japanese Government. 
Living Polymerization of $p$-Methoxystyrene by $\mathrm{I}_{2}$

\section{REFERENCES}

1. M. Szwarc, Nature, 178, 1169 (1956); M. Szwarc, M. Levy, and R. Milkovich, J. Am. Chem. Soc., 78, 2656 (1956).

2. M. Szwarc, "Carbanions, Living Polymers, and Electron Transfer Processes," Interscience Publishers, Inc., New York, N.Y., 1968.

3. M. P. Dreyfuss, Polymer, 6, 93 (1965); C. E. H. Bawn, R. M. Bell, and A. Ledwith, ibid., 6, 95 (1965).

4. e.g., G. A. Olah, Angew. Chem., 85, 183 (1973).

5. J. P. Kennedy, E. Melby, and J. Johnston, $J$. Macromol. Sci.-Chem., A8, 463 (1974).

6. T. Higashimura, O. Kishiro, and T. Takeda, J. Polym. Sci. Chem. Ed., 14, 1089 (1976).
7. J. T. Atkins and F. W. Billmeyer, Jr., J. Phys. Chem., 63, 1966 (1959).

8. C. F. Endres, V. G. Kamath, and C. G. Overberger, J. Am. Chem. Soc., 84, 4813 (1962).

9. T. Higashimura, Y. Imanishi, T. Fukushima, and S. Okamura, Kobunshi Kagaku (Chem. High Polymers), 22, 205 (1965).

10. H. P. Frank, Makromol. Chem., 67, 64 (1963).

11. D. C. Pepper, ibid., 175, 1077 (1974).

12. D. C. Pepper, J. Polym. Sci.; Symp., No. 50, 51 (1975).

13. T. Higashimura, O. Kishiro, K. Matsuzaki, and T. Uryu, J. Polym. Sci. Chem. Ed., 13, 1393 (1975). 